\section{Community Support Team for the Mentally III}

Sir: We appreciate Dr Lucas's comments (Psychiatric Bulletin, December 1995, 19, 788) and are glad he found our report encouraging. However, we fail to share his pessimism and suspect he has over interpreted our paper. Here was a population of individuals with chronic schizophrenia, some of whom had spent 20 years or more in drab and depressing back wards of a large mental hospital, who were resettled successfully into comfortable residential homes. That they have many dependency needs was not neglected and it must be remembered that these were all 24 hour staffed homes. We sought to focus on special problem areas and daily living activities. Many of these patients have continuing behaviours which are problematic and require considerable support and care. Hence they have been deemed unable to live independently. However, we didn't choose to focus on containment as it was not our intention to replant an institutional ethos into this setting.

The goals were not always of great improvement, but sometimes simply to maintain the current position and prevent deterioration. Balancing dependency needs with the need for independence is not something with which we would disagree. The failings of the past have often been an excessive emphasis on dependency needs with the result that illness induced deficits were accentuated.

A focus on normalisation and independence, as far as the patients' capabilities will allow, and building on the strengths of individuals, rather than emphasising their weaknesses, does not imply a neglect of dependency needs.

H. DoYle and T. J. CRAIG

Psychiatric Unit, Northwick Park Hospital, Watford Road, Harrow HA1 3UU

\section{Compulsory community treatment}

Sir: Robert Denton et al (Psychiatric Bulletin, April 1995, 19. 261) refer to the difficult balance "between the medical ethos of the right to treatment and the libertarian ethos of the right to self determination". I think the conflict of principles is even more acute for any proposed community treatment than for detention in hospital. This is particularly the case where patients are overtly well at discharge from detention, but have a vulnerability to mental illness, or where symptoms are thought to be suppressed by medication. Any legislation will need to negotiate the ugly scenario of apparently well individuals living in the community. being given injections of antipsychotic medication against their will.

One way of regulating compulsory community treatment might be for the United Kingdom to adopt a system akin to the south Australian Guardianship board. It functions as a quasi legal body, like the Mental Health Review Tribunal. The emphasis is upon 'due process' with a hearing of evidence and opinion. It considers authorising a package of after care including housing, employment, or training and medication as well as supervision/treatment by psychiatric and social services staff. It would not be a major step to extend the power of Mental Health Review Tribunals to consider the need for compulsory community treatment.

A 'guardianship board' could function by considering converting hospital treatment sections into compulsory community treatment orders, which would be time-limited and subject to review. Such an order could specify the consultants' power to authorise readmission for assessment and treatment in the event of non-compliance, without the need for further detention. It could draw upon the role of the 'Amicus Curiae' or friend of the court in the United States of America. Such an individual, a psychiatrist, criminologist or actuary, could advise on the state of knowledge of 'dangerousness', clarify the issues at stake or comment on management.

Such a system would have a number of advantages. Criteria could be established and legally tested. This would not only protect the rights of patients but would, by sharing risk, go some way to protecting psychiatric staff from assertions of irresponsibility. Although such a system could delay discharge, it might facilitate the discharge of difficult patients and help to identify unmet need. The supervision register indicates the direction of current policy away from the patients' freedom to choose or clinical judgement. Although a 'guardianship board' is a legalistic solution it would appear preferable to current and proposed bureaucratic ones, including the complex Mental Health (Patients in the Community) Bill.

\section{NEIL BOAST}

Hackney Hospital, Homerton High Street, London E9 6BE 